\title{
The Role of Technology in Customer Satisfaction in Public Service Institutions: A Case of Mombasa Water Supply and Sanitation Company
}

\author{
Fatuma Gakuria ${ }^{1}$, Joseph Miyonga ${ }^{2}$ \\ ${ }^{1}$ MBA Student: Jomo Kenyatta University of Agriculture and Technology, Kenya \\ ${ }^{2}$ Lecturer: Jomo Kenyatta University of Agriculture and Technology, Kenya
}

\begin{abstract}
Customer satisfaction refers to the state of mind or the perception that customers have about an organization and its products or services at the time their perceptions have been met or surpassed. This state reflects the lifetime of the product or service experience. Customer service is an integral part of any organization. In a competitive corporate world organizations must identify the key success factors in terms of customer satisfaction because businesses can only be sustainable if the quality of customer service can result in customer satisfaction. Over the past few years, customer satisfaction and technology have become conjoined. Customers today are demanding more and more techno-savvy service that will provide quick and efficient service that will keep pace with the ever changing technological world. Given that customer purchase and re-purchase is the backbone of business sustainability, businesses have no choice but to re-invent customer service in technologically innovative ways. The public service sector, which has long been labeled as "customer averse" must thus toe the line in this era of technological transformation. According to a report on Kenya's ICT integration into public services (2016), currently service areas on the government side, which have embraced ICT, include the iTax portal, Huduma Centres (under the Ministry of Development and Planning), the Integrated Financial Management Information System and the e-Citizen portal. The report further states that the rising number of smart phone users will support growth in mobile money usage and cashless payments, especially as the industry looks to provide new value-added services such as consumer payments, cash disbursements and collections in value chains such as agriculture, healthcare, education, power, water and other fast moving consumer good value chains. However in the public service, and more so in the water sector the service delivery is yet to keep pace with the dynamism of service delivery technology. Services such as meter reading, payment of bills and resolution of customer complaints are still done manually. There has however, been a deliberate effort to incorporate the Mpesa service to ease payments of water bills by the customers. The purpose of this study was to establish whether adoption of technology in key customer service segments will increase customer satisfaction with services provided by the Mombasa Water Supply and Sanitation Company, despite the several challenges in water service provision as outlined. It was hoped that the findings of the research could be generalized and applied to other public service institutions found in the County of Mombasa and those located in other Counties in Kenya. To achieve this, the study reviewed literature on case studies done by other researchers in various part of the globe that sought to determine the relationship between customer satisfaction and technologically enhanced customer service delivery. The research also sought to identify achievements, lessons learnt and challenges of implementing technology enhanced service delivery. The researcher explained the relationship between customer satisfaction and three independent variables using a conceptual framework. Finally the study drew conclusions and recommendations that would contribute to improving customer satisfaction in water services, by the use of technology, and which can also be replicated in other public services. The data collected will be analyzed using descriptive statistics and regression, presented in tables and charts extracted from both MS Excel and Statistical Package for Social Studies (SPSS) software tools. The data collected will be presented in tables and charts extracted from both Ms excel and Statistical Package for Social Sciences (SPSS) software tools version 20.
\end{abstract}

Keywords: Customer Satisfaction, Public service, Technology, Non-revenue water, Customer experience

\section{Introduction}

The public sector forms an important segment of an economy. Any development in public sector performance would have a direct effect on the economic growth of a country. However, this implies that a lot of focus needs to be directed towards efficiency that will allow the public sector to have any tangible effect on development. Public institutions must work in the right manner and at least cost[1]. Amidst the growing demand for better services by the customers, public institutions must embrace new models of service delivery.

According to [2] there was need for public institutions to not only do things right and in the right way and cost, but more so, the institutions had to be open to new models of service delivery. This underlines the need for public institutions to embrace technology in order to enhance efficiency and effectiveness in service delivery and enhance customer satisfaction.

Customer satisfaction is a marketing term which measures how products and services supplied by a company meet or surpass customer expectation. It can also be looked at as the number of customers, or percentage of total customers, whose reported experience with a firm, its products, or its services (in other word "the ratings") exceeds specified satisfaction goals. Customer satisfaction is seen as a key performance indicator within business and is a key item of the Balanced Scorecard[3]. In a competitive marketplace where businesses compete for customers, customer satisfaction is seen as a key differentiator and increasingly has become a key element of business strategy.

Unlike in the public sector, the private sector upholds customer satisfaction and loyalty - which is secured through 


\section{International Journal of Science and Research (IJSR) \\ ISSN (Online): 2319-7064}

Index Copernicus Value (2015): 78.96 | Impact Factor (2015): 6.391

high-quality products and services which meet customer needs and which provide value for money. This is seen as essential for survival of business. In the public sector the concepts of service quality, customer satisfaction and customer loyalty have not been a priority mainly because public services have a built-in customer [4]. According to [5] public services tend not to go out of businessand the abolishment or closing down of a public organization is fairly rare. [5] goes on to add that many public services are even successful when their customer base shrinks, either because the problem they have are created for is solved, or because they have been successful in discouraging clients of whom many are involuntary clients.

In the recent past, technology has been setting pace in customer service on a global scale. In the last few decades, IT applications have changed the landscape of the service industry [6]. One of the key contributors to future marketing success, for both large and small firms alike, will be the exploitation of technology, which will facilitate the use and management of information. Through the use of technology, institutions are presently re-engineering the way in which business and marketing of their goods and services is being conducted. The approaches to marketing have progressed from product-centered to customer-centered approaches. Marketers are now more than ever before, focusing on customer experience with products and services.

According to [7] the impact has been mainly profound in the services arena through the development of self-service technologies (SSTs). Past studies on the adoption of technology in different services such as the hospitality sector confirm that a growing number of consumers prefer DIY (Do-It-Yourself) opportunities and in some cases are eager to use SSTs [8]. According to [9] technology is making it easier than ever to improve diversity levels and reduce discrimination, by providing greater transparency and insight for the service industry.

Recently, the mobile service sector has experienced disruptive change caused by smartphones and mobile application (app) services in a short period of time. The numbers of app services have increased explosively with the rise of mobile open markets [10]. The importance of customer experience is emphasized by [11] who attests that the interest in customer experience (CX) has increased exponentially over the past decades amongst service researchers and practitioners.

Over the past half-decade, Kenya has emerged, seemingly from nowhere, as a hotbed of innovation in the area of mobile money-transfer systems and for other types of software and services for mobile devices. According to [12] nearly 70 percent of Kenyan adults transfer money to each other via their mobile phones, the highest percentage of any country on earth, and more than US\$320 million dollars are transferred via Kenyan mobile phones each month. Kenya has become host to a flourishing ecosystem where numerous software applications, services and even social habits have emerged from the country's aptitude, and appetite, for mobile transaction platforms [12]. Technological transformation in the business arena is aimed at the customer and ensuring that the customer gets a unique customer experience. [13] attest to the fact that internet technologies have completely paved the way to the concept of an electronic economy and that they have enabled the creation of innovative business approaches in the field of sales, production, service delivery and purchases.

\subsection{Statement of the problem}

The Public Sector is crucial for attaining Kenya's development agenda. The agenda has been placed solely in the hands of public service institutions which have been assigned targets to ensure that the public institutions remain on course with the development blueprint [14]. The key concern for the Government is that the common citizens must have their basic needs met. Every citizen is entitled to food, water, shelter, security, medical care and education amongst other rights, as enshrined in the Millennium development Goals and Vison 2030.

Water services by the Mombasa Water Supply and Sanitation Company (MOWASSCO) thus continue to be unsatisfactory given the key challenge of financial sustainability. Poor services invariably affects the degree of customer satisfaction. It is against this backdrop that this research seeks to establish whether integrating technology in all aspects of service delivery can mitigate the challenges encountered in water service delivery and thereafter improve services and customer satisfaction of the residents of Mombasa County.

Over the last two years MOWASSCO has made some efforts in adopting digital payment of bills through the Mpesa method. Digital payment is progressing albeit at a slow pace, given that a large number of customers can still be seen queueing to pay their bills manually. The utility is however lax in adopting new meter reading technologies. The bulk of the customer complaints are related to meters, where meters are malfunctioning. Majority of customers also feel that their bills are always estimated leading credence to the fact that there are challenges in meter reading. On the other hand meter readers of the utility often face challenges while accessing meter points in individual homes ranging from secured gates to water logged meters which makes reading difficult [15].

The water reticulation system in Mombasa is old and dilapidated and is prone to leaks and bursts. Coupled with this fact is the challenge of illegal connections done by unscrupulous persons who connect to the system unprofessionally leading to leaks. Leaks and bursts may go for days an end without being reported leading to excessive loss of water. However, residents are lax in reporting leaks in their areas and have tended to ignore the issue either out of ignorance or lethargy to report the issue. There appears to be lack of effective communication between the utility and the customers which needs to be addressed.

\subsection{Research Objectives}

The general objective of the study was to establish the impact of technology on customer satisfaction in the public sector in relation to Mombasa Water Supply and Sanitation Company.

\section{Volume 6 Issue 1, January 2017




\section{International Journal of Science and Research (IJSR) \\ ISSN (Online): 2319-7064}

Index Copernicus Value (2015): 78.96 | Impact Factor (2015): 6.391

Specific objectives of the study were:

1) To find out the impact of technology-enhanced nonrevenue water control on customer satisfaction in Mombasa Water Supply and Sanitation Company

2) To establish the influence of technology-enhanced meter reading on customer satisfaction in Mombasa Water Supply \& Sanitation Company.

3) To determine the extent of technology-enhanced communication on customer satisfaction in Mombasa Water Supply \& Sanitation Company.

\section{Theoretical Literature}

Ugandan writer and the then Managing Director of National Water and Sewerage Corporation of Uganda in his famous book Making Public Enterprises Workargued that the problem hindering public enterprises from performing was largely mismanagement [16]. However, [16] asserts that any good business enterprise must strive to ensure the quality of its products, its packaging, mode and speed of delivery, its price structure and public relations were geared towards the satisfaction of the needs and expectations of its customers. [16] observed that without a satisfied customer who is willing to pay for what is produced by the organization, be it water or something else, the business can never survive. Thus customer satisfaction was the foundation of a successful business.

Festinger's theory of dissonance (1957) forms the basis for the theory of assimilation. The theory of dissonance states that the consumer makes a sort of cognitive comparison between the expectations regarding the product and the product's perceived performance. If there is a discrepancy between expectations and the product's perceived performance, the dissonance will not fail to appear. This point of view on post-usage evaluation was introduced in the literature discussing satisfaction under the form of the theory of assimilation.

According to Anderson, the consumers try to avoid dissonance by adjusting their perceptions of a certain product, in order to bring it closer to their expectations. In a similar way, the consumers can reduce the tension resulted from the discrepancy between expectations and the product's performance, both by distorting the expectations so that they could be in agreement with the product's perceived performance, and by increasing the level of satisfaction through minimizing the relative importance of experimental disconfirmation.

The theory presumes the consumers are motivated enough to adjust both their expectations and their product performance perceptions. If the consumers adjust their expectations or product performance perceptions, dissatisfaction would not be a result of the post-usage process. Consumers can reduce the tension resulting from a discrepancy between expectations and product/service performance either by distorting expectations so that they coincide with perceived product performance or by raising the level of satisfaction by minimizing the relative importance of the disconfirmation experienced [17] Some researchers have discovered that the control on the actual product performance can lead to a positive. relationship between expectations and satisfaction. [18] Consequently, it is assumed that dissatisfaction could never appear unless the evaluation process began with the customers' negative expectations.

The diffusion of innovation theory analysis how the social members adopt the new innovative ideas and how they made the decision towards it. Both mass media and interpersonal communication channel is involved in the diffusion process. The theory heavily relies on Human capital. According to the theory, innovations should be widely adopted in order to attain development and sustainability [19]. In real life situations the adaptability of the culture played a very relevant role where ever the theory was applied. Rogers proposed four elements of diffusion of innovations they are: Innovations - an idea, practice, or object perceived as new by an individual. It can also be an impulse to do something new or bring some social change, Communication Channel The communication channels take the messages from one individual to another. It is through the channel of communication the Innovations spreads across the people. It can take any form like word of mouth, SMS, any sort of literary form etc, Time - It refers to the length of time which takes from the people to get adopted to the innovations in a society. It is the time people take to get used to new ideas. For an example consider mobile phones it took a while to get spread among the people when it is introduced in the market, Social System - Interrelated network group joint together to solve the problems for a common goal. Social system refers to all kinds of components which construct the society like religion, institutions, groups of people etc.

During the last years of 90's the mobile phones were introduced to common people even though it was there in market the cost was much higher. Roger's theory of diffusion of innovation can be apprehended by understanding how the people accepted and get used for mobile phones. When it was introduced it wasn't something which comes with 500 plus killer applications as today it was merely a portable land line.

\section{Conceptual Framework}

The Conceptual Framework will concentrate on three key areas which effect customer satisfaction. In the framework customer satisfaction is the dependent variable while technology enhanced NRW control, technology enhanced meter reading and technology enhanced communication are the independent variables. 


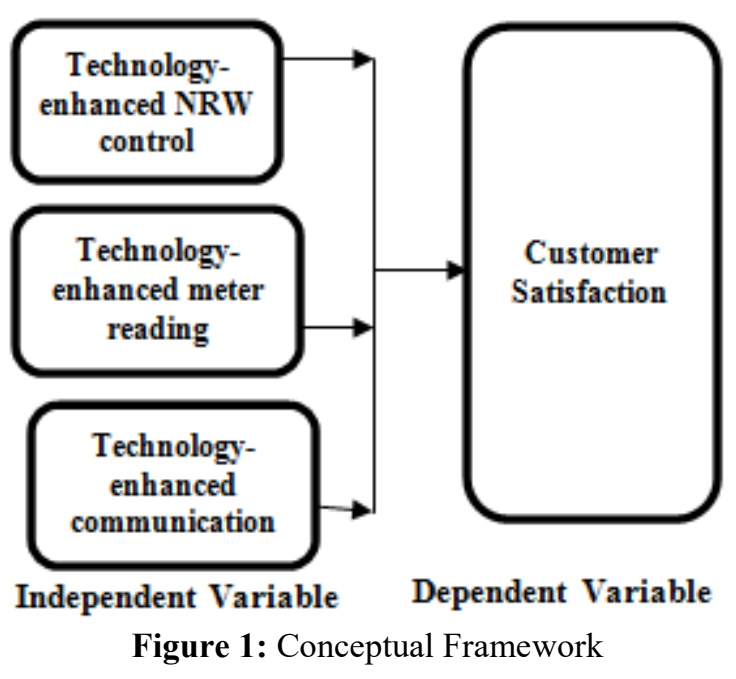

\section{Empirical Review}

The study of [20]: Understanding the Role of Complaint Handling on Consumer Loyalty in Service Relationship. In this study the researchers explore the role of 5 drivers of loyalty: customer usage level, service pricing, service quality, membership in the firm's loyalty program, and satisfaction with complaint handling. The effects of these drivers may differ for customers who complain versus who do not complain. The questionnaire of this study was administrated to passengers of a major European airline. On randomly selected routes between Germany, Austria, and Switzerland, passengers is randomly selected flights and seat numbers received questionnaires with total amount of two thousands and six hundreds. The researchers found that the satisfaction with complaint handling was key to consumer recommendation of the service to others.

The study of [21]: The Recovery Paradox: The Effect of Recovery Performance and Service Failure Severity on PostRecovery Customer Satisfaction. In this study the researchers investigated the recovery paradox, the proposition that superior recovery can leave the customer as satisfied, if not more satisfied, than if nothing had gone wrong by examining the impact of service failure severity and the recovery performance on post-recovery satisfaction. Passengers from 50 departures were included in the sample, and all carriers were represented by several departures. In total, 237 passengers were approached and asked to participate in this study. The researcher suggests that the greater service failure severity the greater the recovery performance necessary to convert the customers' dissatisfaction into satisfaction and the more difficult it should be for the service provider to achieve full recovery. Results show that service failure severity must be very modest and the recovery effort must be superior.

The study of [22]: Analysis of the Role of Complaint Management in the Context of Relationship Marketing. This research aims to contribute to the relationship-marketing strategy by studying the role of complaint management in long-term relationships. The findings confirm the importance that theory accords to the relationship-marketing strategy, and also provide evidence for the importance of complaint management. Thus having a good complaint- handling system and trained and motivated staff who are fully committed to the firm's objectives are fundamental requisites for firms to be able to build a stable customer portfolio.

\section{Research Gap}

Most of the research on effects of technology on organizational customer satisfaction is scanty, and mainly focuses on effects of customer satisfaction on organizational performance or growth and thus the need to carry out research in other occupations as well both in public and private sector to know if there would be any variation in respondents response in different occupations altogether.

Studies on the effect of technology on customer satisfaction indicate a connectivity [23] but do not seem to identify the causal connectivity between the two, as well as identify the strength of the relationship between technology and organizational growth. It is thus important to carry out research to identify to what extent technology affects organizational growth. Previous research has primarily focused on the positive effects of technology on customer satisfaction, [24].

\section{Research Methodology}

In addition, a research design is a blue print which facilitates the smooth sailing of the various research operations, thereby making research as efficient as possible hence yielding maximum information with minimal expenditure of effort, time and money.

This study used a descriptive research design. Descriptive research refers to a set of methods and procedures that describe variables. It involves gathering data that describe events and then organizes, tabulates, depicts, and describes the data. The design is considered appropriate because it also provides an in depth and comprehensive inquiry required to be conducted to have a description of the subject under study.

The total population of the study will be three hundred and ninety two (360) with 60 derived from each of the six administrative sub-county regions under MWSSC. The target population is 360 because it is an ample representative figure as per data supplied by the Mombasa Water Supply and Sanitation Company. From the target population of 360 , a sample size of $30 \%$ will be taken giving a sample base of consisting of respondents from Likoni, Jomvu, Mvita, Changamwe, Kisauni and Nyali sub-counties.

[9] describe data analysis as a process of bringing order, structure and meaning to the multitude of collected data. Quantitative data, which will be collected using structured questionnaires, will be analyzed using the Statistical Package for Social Scientists (SPSS) version 20, which offers extensive data handling capability and numerous statistical analysis routines that can analyze small to very large data statistics and can generate descriptive statistics [12]. 


\section{International Journal of Science and Research (IJSR) \\ ISSN (Online): 2319-7064}

Index Copernicus Value (2015): 78.96 | Impact Factor (2015): 6.391

The qualitative data was organized according to answers to open ended questions in the questionnaire and analyzed through content analysis. According to [12] content analysis is the process of analyzing verbal or written communications in a systematic way to measure variables qualitatively. Presentation of data was in form of Tables, Pie-charts and Bar graphs only where it provides successful interpretation of the findings. Descriptive data was provided in form of explanatory notes.

To test whether technology has an impact in enhancing customer satisfaction at MWSSC, regression analysis was used in the data analysis process using the regression model. Regression applications in which there are several independent variables, $x_{1}, x_{2}, \ldots, x_{k}$.Enhanced employee Performance $=\beta_{0}+\beta_{1} \mathrm{TENC}_{1}+\beta_{2} \mathrm{TEMR}_{2}+\beta_{3} \mathrm{TEC}_{3}+\varepsilon$

Multiple regression model will be used to determine the importance of each variables with respect to the customer satisfaction at MWSSC.

$Y=\beta_{0}+\beta_{1} X_{1}+\beta_{2} X_{2}+\beta_{3} X_{3}+\beta_{4} X_{4}+\varepsilon$

$\mathrm{Y}=$ the dependent variable.

$\beta_{0}=$ constant term.

$\beta_{1} X_{1}-\beta_{4} X_{4}=$ independent variables.

$\varepsilon=$ error term.

\section{Results and Discussion}

\begin{tabular}{|c|c|c|c|c|}
\hline \multicolumn{6}{|c|}{ Correlations } \\
\hline & CS & TEN & TEMR & TEC \\
\hline CS & 1 & 0.948 & 0.896 & 0.823 \\
\hline TEN & 0.948 & 1 & 0.92 & 0.81 \\
\hline TEMR & 0.896 & 0.92 & 1 & 0.835 \\
\hline TEC & 0.823 & 0.81 & 0.835 & 1 \\
\hline
\end{tabular}

Key: TEN-Technology enhanced NRW control, TEMRTechnology enhanced Meter reading, TEC-Technology enhanced Communication, CS-Customer Satisfaction.

There is a strong positive coefficient of correlation of 0.220 between of Customer Satisfaction (dependent variable) and Technology enhanced NRW (independent variable) indicating that Technology enhanced NRW has a significant effect on Customer Satisfaction in MWSSC ( Mombasa Water Supply and Sanitation Company). There is a strong positive correlation of 0.896 between Customer Satisfaction (dependent variable) and Technology enhanced Meter reading(independent variable) indicating that internal rate of returns has a strong influence on the Customer Satisfaction of MWSSC. There is a strong positive correlation of 0.823 between Customer satisfaction (dependent variable) and technology enhanced communication (independent variable) indicating that technology enhanced communication has a significance influence on customer satisfaction at MWSSC.

\begin{tabular}{|c|c|c|c|c|c|c|c|c|c|}
\hline \multicolumn{10}{|c|}{ Model Summary } \\
\hline \multirow{2}{*}{ Model } & \multirow{2}{*}{$\mathrm{R}$} & \multirow{2}{*}{ R Square } & Adjusted R & Std. Error of the & \multicolumn{5}{c|}{ Change Statistics } \\
\cline { 5 - 10 } & & Square & Estimate & R Square Change & F Change & df1 & df2 & Sig. F Change \\
\hline 1 & $.955^{\mathrm{a}}$ & 0.913 & 0.899 & 0.22983 & 0.913 & 65.294 & 4 & 25 & 0 \\
\hline \multicolumn{10}{|c|}{ a. Predictors: (Constant), CustomerSatisfaction TEN, TEMR, TEC } \\
\hline
\end{tabular}

From the table above, $91.3 \%$ of the relationship between the Customer satisfaction levels at MWSSC is explained by the independent variables namely; Technology enhanced NRW control, Technology enhanced Meter reading and Technology enhanced Communication. The remaining 8.7\% is the relationship by other variables.

\begin{tabular}{|l|l|c|c|c|c|c|}
\hline \multicolumn{7}{|l|}{ ANOVA $^{\text {a }}$} \\
\hline \multicolumn{2}{|l|}{ Model } & $\begin{array}{l}\text { Sum of } \\
\text { Squares }\end{array}$ & df & Mean Square & F & Sig. \\
\hline \multirow{4}{*}{1} & Regression & 13.796 & 4 & 3.449 & 65.294 & $.000^{\mathrm{b}}$ \\
\cline { 2 - 7 } & Residual & 1.321 & 25 & 0.053 & & \\
\cline { 2 - 6 } & Total & 15.117 & 29 & & & \\
\hline
\end{tabular}

The test of ANOVA was also carried out to test whether infusion of technology influences customer satisfaction in public Institutions (MWSSC). When the test was run at 0.05 significance level, the $\mathrm{p}$ value was 0.000 . If $\mathrm{p}$ value $(0.000)$ is less than $\alpha(0.05)$ then the result is significant inferring technology does affect the customer satisfaction rates at public institutions mainly MWSSC.

\section{Recommendations}

The organizational managers should thus supervise personnel interacting with clients or customers so as to ensure that anyone not having the fundamentally required customer relations is transferred eventually. In the usage of technology, security is a fundamental and essential requirements and thus ensuring that proprietor MWSSC technology are protected from being infringed by other entities is essential. Ensuring that also all organizational technologies have a failsafe and over ride system to improve effectiveness is also an essentiality.

Finance being a major impediment to the implementation of advancements in technology that would eventually play a contributory role in customer satisfaction in MWSSC, the government should thus ensure it allocates enough financial resources so as to aid the organization in it's objectives. The resultant feature of such a practice will be an eventually satisfied customer base.

\section{Future Scope of the Study}

There is an inherent need to validate and enhance future research using random sampling that is more diversified in nature. 


\section{International Journal of Science and Research (IJSR) \\ ISSN (Online): 2319-7064 \\ Index Copernicus Value (2015): 78.96 | Impact Factor (2015): 6.391}

There is also the need to carry out future research on the effects of service quality to customer satisfaction and loyalty. The future study must strive to delve deeper into the subject matter.

Future studies should also be carried out to compare the customer satisfaction levels between the different water and sanitation entities in the country.

\section{References}

[1] Bengtsson, M. (2008). Standardization issues in condition based maintenance. In proceedings from the 16th Conference of Condition Monitoring and Diagnostic Engineering Management, Sweden, Växjö: Växjö University Press.

[2] Kibblewhite, A. (2011).Role of public sector performance in economic growth. Wellington: Institute of Policy Studies.

[3] Alsyouf, I. (2006). Measuring maintenance performance using a balanced scorecard approach. Journal of Quality in Maintenance Engineering, (12 (2), 133 - 149.

[4] Akinboade,O., Kinfack, E., \& Mokwena, M. (2012). An analysis of citizen satisfaction with public service delivery in the Sedibeng district municipality of South Africa. International Journal of Social Economics, Vol. 39 No. 3, pp. 182- 199.

[5] Steven Van de Walle, (2016). When public services fail: a research agenda on public service failure", Journal of Service Management, Vol. 27 Iss 5.

[6] Kaushik A. R. \& Rahman Z., (2015). Innovation adoption across self-service banking technologies in India. International Journal of Bank Marketing, Vol. 33 Iss: 2, pp.96- 121 .

[7] Makokha, H., (2014). External factors that influence delivery of quality services in public institutions. A case of the Department of Immigration, Coast Region. JKUAT library.

[8] Jaakkola, E., Helkkula, A. and Aarikka-Stenroos, L. (2015). Service experience co-creation: conceptualization, implications, and future research directions. Journal of Service Management, Vol. 26 No. 2, pp. 182-205.

[9] Hipps, C., (2016). How technology can fuel the diversity challenge. Strategic HR Review, Vol. 15 Iss 5 pp.

[10] Park, J. K. S. L. Y., (2016). A visual context-based market analysis of mobile application services. Management Decision, Vol. 54 Iss 9.

[11]Lipkin, M., (2016). Customer experience formation in today's service landscape. Journal of Service Management, Vol. 27 Iss 5.

[12] Mengistu, A. \& Imende S. (2013) Kenya's Mobile Tech Revolution.

[13] Lecic-Cvetkoic, D., Omerbegovic-Bijelovic, J., Zaric, S., \&Janicic, R., (2016). E-banking application in business companies - A case study of Serbia. Information,Development.Vol. 32, 4: pp. 762-776.

[14] Bedeian, A., G. (2013). Management (3rd ed.). New York: Dryden Press.

[15]DuBrin, A., J. (2012). Essentials of management. Mason, $\mathrm{OH}$ : Cengage South-Western.
[16] Muhairwe, W. T., (2009). Making public enterprises work. Kampala: Fountain publishers.

[17] Olson, J., \& Dover, P. (2009), Disconfirmation of consumer expectations through product trial. Journal of Applied Psychology: Vol.64, pp.179-189.

[18] Anderson, R., E. (2013). Consumer Dissatisfaction: The Effect of Disconfirmed Expectancy on Product Performance, Journal of Marketing, Research, 10, p.3844

[19]Diggle, T., (2013). Water: how collective intelligence can address this challenge. Foresight. Vol. 15 Iss: 5, pp.342-353

[20] Rothenberger, S., Grewal, D., \& Iyer, G. (2008). Understanding the Role of Complaint Handling on Consumer Loyalty In Service Relationships. Journalof Relationship Marketing, 7. http://dx.doi.org/10.1080/15332660802516029.

[21] McCollough, M. (2009). The Recovery Paradox: The Effect of Recovery Performance and Service Failure Severity on Post-Recovery Customer Satisfaction. Academy of Marketing Studies Journal, 13(1).

[22] Alvarez, I., Casielles, R., \& Martin, A. (2011). Analysis of The Role of Complaint Management in The Context of Relationship Marketing. Journal of Marketing Management, 27(1-2).

[23] Luthans, F. (2011). Organizational behavior (12th ed.) New York, NY: McGraw-Hill.

[24] Cole, G.A. (2009). Management Theory and Practice (6th ed.). Bedford Row, London: Cengage

Volume 6 Issue 1, January 2017

www.ijsr.net 